\title{
Histopathological, Radiological and Demographic Factors Predicting the Response to Neoadjuvant Therapy for Rectal Cancer
}

Emine YILDIRIM ( $\square$ opdreyildirim@gmail.com )

Gaziosmanpasa Taksim Egitim ve Arastirma Hastanesi https://orcid.org/0000-0003-2733-402X

\section{Sibel Bektas}

Gaziosmanpasa Taksim Egitim ve Arastirma Hastanesi

\section{Zekeriya Pelen}

Gaziosmanpasa Taksim Egitim ve Arastirma Hastanesi

Irem Yanik

Gaziosmanpasa Taksim Egitim ve Arastirma Hastanesi

Ahmet Muzaffer Er

Gaziosmanpasa Taksim Egitim ve Arastirma Hastanesi

\section{Ferhat Cengel}

Gaziosmanpasa Taksim Egitim ve Arastirma Hastanesi

\section{Perihan Ozkan Gumuskaya}

Okmeydani Egitim ve Arastirma Hastanesi: Turkiye Cumhuriyeti Saglik Bakanligi Okmeydani Egitim ve Arastirma Hastanesi

\section{Research Article}

Keywords: Locally advanced rectal cancer, response to neoadjuvant therapy, pathological complete response, lymphovascular invasion, perineural invasion

Posted Date: August 10th, 2021

DOI: https://doi.org/10.21203/rs.3.rs-785035/v1

License: (c) (1) This work is licensed under a Creative Commons Attribution 4.0 International License. Read Full License

Version of Record: A version of this preprint was published at Journal of Gastrointestinal Cancer on September 1st, 2021. See the published version at https://doi.org/10.1007/s12029-021-00697-9. 


\section{Abstract}

\section{Background/aim}

While the treatment for early stage rectal cancer is surgery, when a diagnosis is made at a locally advanced stage, it is recommended to start treatment with neoadjuvant chemoradiotherapy. Therefore, it is important to determine which patients will respond best to neoadjuvant treatment. The aim of this study was to investigate which hematological, histopathological, and radiological parameters can predict the response to chemoradiotherapy.

Methods and materials

A retrospective examination was made of 43 patients who underwent surgery following neoadjuvant chemoradiotherapy because of locally advanced stage rectal cancer. Demographic data were collected from the patient files, and the radiological, histopathological and laboratory findings before neoadjuvant chemoradiotherapy were compared with the findings after treatment.

Results

In the postoperative evaluation, a pathological complete response was determined in $25.50 \%$ of the patients. Lymphovascular invasion, perineural invasion and absence of necrosisis were seen to be statistically related to major response $(p<0.05)$, and in patients where the tumor was closer than $6 \mathrm{~cm}$ to the anal verge, the response was better

Conclusion

When the findings were examined, histopathological lymphovascular invasion, perineural invasion, the presence of necrosis, and the anal verge distance were evaluated as parameters predicting the response to neoadjuvant chemoradiotherapy in rectal cancer.

\section{Introduction}

According to the 2018 GLOBOCAN data of the World Health Organisation (WHO), colorectal cancer (CRC) constitutes $11 \%$ of all cancer diagnoses, is the third most commonly diagnosed cancer worldwide, and is the third most common cause of cancer-related deaths [1]. Rectal cancers are defined as tumors developing in the $15 \mathrm{~cm}$ section from the anal verge, and these tumors which constitute $30 \%$ of colorectal cancers are associated with worse clinical outcomes [2]. The gold standard treatment in surgery for rectal cancer is to remove the tumor and drained lymph nodes to obtain R0 resection. While surgical treatment is sufficient in early stage rectal cancer, the standard treatment in locally advanced stage rectal cancer (LARC) is neoadjuvant chemoradiotherapy (NCRT) followed by radical surgery [3].

While subcluster resistance is seen in approximately $20 \%$ of patients receiving neoadjuvant therapy, $50-$ $60 \%$ have a partial response, and pathological complete response (PCR) has been reported in 
approximately $20 \%[3,4]$. Most recent studies have shown that mean survival is increased and local recurrence is significantly decreased in rectal cancer patients with PCR after NCRT [4-6]. However, when clinical studies that have compared NCRT with adjuvant chemoradiotherapy (ACRT) are examined, the rate of local recurrence and systemic toxicity has been found to be lower, and patient compliance higher compared to postoperative radiotherapy, but this has caused no significant difference in survival $[7,8]$. In addition, when compared with adjuvant therapy, NCRT increases the chance of protecting the sphincter against tumors located in the lower rectum [9].

Although neoadjuvant therapy provides great advantages, there are some disadvantages of radiotherapy, which is an inseparable part of the therapy. Not every patient has a positive response to radiotherapy and therapy-related toxicity may develop, which has a negative effect on the quality of life of the patient [10]. Moreover, by causing excessive edema, neoadjuvant radiotherapy can lead to loss of the surgical field, which makes surgery more difficult, especially in the narrow male pelvis [11]. At this stage, it is important to be able to identify which patients will be benefit from NCRT, before application.

Factors which are thought to have an effect on PCR include the tumor size and stage, distance to the anal verge, the time interval between radiotherapy and surgery, mucinous histology, tumor differentiation, and circumferential extent and preoperative CEA level [12].

In addition to these factors, investigation was made in this study of histopathological findings such as tumor grade, differentiation, necrosis, lymphovascular invasion (LVI), and perineural invasion (PNI), the characteristics evaluated on magnetic resonance imaging (MRI), laboratory findings, and demographic findings, with the aim of determining which group of patients receiving NCRT would benefit most from the treatment, and to evaluate which patients were included in the group with $20 \%$ resistance.

\section{Materials And Methods}

\section{Data collection}

The study included 43 patients diagnosed with LARC, who were operated on in xxxxxx hospital after receiving NCRT between April 2014 and December 2019. The study inclusion criteria were as follows: 1-) Histopathological diagnosis of adenocarcinoma, 2-) Tumor localisation in the first $15 \mathrm{~cm}$ from the anal

verge, and 3-) A diagnosis of clinically locally advanced stage rectal cancer $\left(T_{3-4} N_{0}\right.$ and $\left.T_{\text {any }}, N_{1-2}\right)$. The study exclusion criteria were defined as 1-) A previous or concomitant malignancy, 2-) Accompanying inflammatory bowel disease, 3-) R1-2 resection applied, 4-) Emergency or palliative resection applied during treatment, 5-) Follow-up of patients with local excision after NCRT or a watch-and-wait strategy, and 6-) Patient rejection of completion of neoadjuvant treatment.

Preoperative metastasis screening was applied to all the patients, and evaluation was made with pelvic MRI, colonoscopy, and rectal EUS prior to NCRT. 
Data were retrieved from the medical records of each patient, in respect of medical history, age, sex, chemoradiotherapy regimen of NCRT, surgical method, pathological results (such as histological type, histological differentiation, histological grade, necrosis, $\mathrm{PNI}, \mathrm{LVI}$ ) and laboratory data. The tumor size (T stage), lymph node status ( $\mathrm{N}$ stage), presence of metastasis ( $\mathrm{M}$ stage) and the American Joint Committee on Cancer (AJCC) stage for each patient were obtained by reviewing the cancer registry data [13].

\section{MRI Technique and Image Interpretation}

MR imaging studies were performed using a 1.5 Tesla (GE Medical system, Milwaukee, WI, USA) MR unit with a sixteen-channel phased array body coil. All MR images were reviewed by a radiologist with 9 years of experience in interpreting abdominopelvic MR imaging (FC), on a PACS imaging workstation (Infinitt PACS; Infinitt Healthcare, Seoul, Korea). The main pulse sequences in image interpretion were T2weighted sequences. Circumferential resection margin (CRM) involvement, Extramural venous invasion (EMVI) status, and $\mathrm{T}$ and $\mathrm{N}$ stage were assessed according to the literature. EMVI was defined as the presence of tumor cells within blood vessels beyond the muscularis propria $[14,15]$.

\section{Chemoradiotherapy}

Patients were applied with long-term radiotherapy (RT) preoperatively at a total 50.4 Gy dose in 25 fractions for 5 weeks followed by 5.4 Gy boost RT, and at the same time, FOLFOX ( $5 \mathrm{FU}+$ leucovorin + oxaliplatin) or CapeOX (capecitabine + oxaliplatin) chemotherapy (CT). Following the NCRT, the patients were evaluated with colonoscopy and pelvic MRI, and were then admitted for surgery at $6-8$ weeks after the end of the treatment.

\section{Surgery}

As the surgical technique, total mesorectal excision was applied with high ligation of the inferior mesenteric artery.

\section{Assessing Chemotherapy Response}

After collection of the demographic data and time from diagnosis to surgery from the patient files, the radiological, histopathological, and laboratory findings before NCRT were compared with the posttreatment findings. The findings of mesorectum invasion, lymph node involvement in the mesorectum, and extramural venous invasion were evaluated on pelvic MRI findings. The preoperative period was calculated as the time from diagnosis to surgery. To determine the tumors which would benefit most from NCRT, the tumor properties were examined by evaluating the histopathological tumor grade, differentiation, and the presence of necrosis, PNI, and LVI. The presence of LVI, PNI and necrosis in the histopathological samples is shown in Fig. 1.

The College of American Pathologists Tumor Regression Grading (CAP-TRG) system was used to evaluate the response to neoadjuvant chemotherapy. According to this system, responses are evaluated as Grade 0; No viable cancer cells (complete response). Grade 1; Single cells or small groups of cancer 
cells (moderate response). Grade 2; Residual cancer cells with evident tumor regression but more than single cells or rare small groups of cancer cells (minimal response). Grade 3; Minimal or no tumor killed or extensive residual cancer (poor response) [16].

From the routine blood tests performed 10-15 days before NRCT, CEA, hemoglobin level, and the neutrophil-lymphocyte ratio were calculated, and the relationship with response to NRCT was evaluated. NLR was calculated as the ratio of absolute neutrophil count to absolute lymphocyte count in this blood sample.

All subsequent analyses were made by separating the patients into major (regression grades 0 and 1 ) and minor (grades 2 and 3 ) responses.

\section{Clinical outcomes}

In the prognosis, disease-free survival (DFS) was evaluated as the time from curative surgical treatment to the occurrence of local or distant recurrence of the disease, and overall survival (OS) as the time from curative surgery applied for treatment to disease-related death.

\section{Follow-up}

Postoperatively, the patients were called for follow up once every 3 months for the first 2 years, and then at 6-month intervals between the third and fifth years. In the follow-up examinations, a routine physical examination was made, full blood tests were performed and pulmonary radiographs and full abdominal ultrasonography were taken. At the end of the first year, colonoscopy was applied, and when necessary, evaluation with computed tomography (CT) and MRI.

\section{Statistical analysis}

Data obtained in the study were analyzed statistically with SPSS vn. 21 software. Conformity of continuous variables to normal distribution was assessed with the Shapiro-Wilk test. In the comparisons of mean values showing normal distribution according to the major and minor groups, the Student's t-test was applied and for those not showing normal distribution, the Mann Whitney U-test was used. The Chisquare test and Fisher's Exact test were applied in the analysis of categorical data. The effect of the variables on the groups was evaluated with Multivariate Logistic Regression analysis. A value of $p<0.05$ was accepted as statistically significant.

\section{Results}

Between April 2014 and December 2019, 72 patients with a diagnosis of rectal cancer were operated on in our hospital. Of these, 53 were locally advanced stage and NCRT was planned. Emergency surgery was performed in 5 patients as perforation developed during NCRT, 3 patients refused surgery because of the risk of colostomy, and local excision was performed in 2 patients. Analysis was made of 43 patients who met the study criteria. 
The patients comprised 24 males and 19 females with a mean age of 54 years (range, 48-65 years). All the patients were diagnosed with adenocarcinoma, 2 patients at stage 2a, 3 at stage 2b, 5 at stage $3 a, 17$ at stage $3 b$, and 6 at stage $3 c$. All the patients received long-term RT followed by POLFOX or capeOX CT regimen. No significant relationship was determined between pathological response and the treatment regimen received.

Following NCRT, 11 patients showed PCR, and according to the CAP-TRG system, 3 patients had Grade 1 response, 20 patients had Grade 2, and 8 patients had Grade 3 response.

Summary of the demographic, histopathological and laboratory findings of the patients according to response are shown in Table 1. 
Table 1

Summary of the demographic, histopathological and laboratory findings of the patients according to response

\begin{tabular}{|c|c|c|c|c|c|c|c|}
\hline & \multicolumn{2}{|c|}{ Major Response } & \multicolumn{2}{|c|}{ Minor Response } & \multicolumn{2}{|l|}{ Total } & $P$ value \\
\hline & \multicolumn{2}{|c|}{ Mean \pm SD } & \multicolumn{2}{|c|}{ Mean \pm SD } & \multicolumn{2}{|c|}{ Mean \pm SD } & \\
\hline Age (year) & \multicolumn{2}{|c|}{$55,10 \pm 12,6$} & \multicolumn{2}{|c|}{$55,90 \pm 11,7$} & \multicolumn{2}{|c|}{$55,65 \pm 11,85$} & $0,848^{a}$ \\
\hline Preoperative time (day) & \multicolumn{2}{|c|}{$118 \pm 19,60$} & \multicolumn{2}{|c|}{$128 \pm 27,5$} & \multicolumn{2}{|c|}{$124 \pm 25,4$} & $0,508^{b}$ \\
\hline Anal verge $(\mathrm{cm})$ & \multicolumn{2}{|c|}{$4,80 \pm 2,24$} & \multicolumn{2}{|c|}{$7,30 \pm 3,37$} & \multicolumn{2}{|c|}{$31,14 \pm 19,36$} & $0,013^{b}$ \\
\hline CEA (ng/mL) & \multicolumn{2}{|c|}{$6,8 \pm 10,8$} & \multicolumn{2}{|c|}{$10,4 \pm 14,3$} & \multicolumn{2}{|c|}{$9,24 \pm 13,24$} & $0,484^{b}$ \\
\hline NCRT_If & \multicolumn{2}{|l|}{$1 \pm 0,4$} & \multicolumn{2}{|c|}{$1,5 \pm 1,4$} & \multicolumn{2}{|c|}{$1,33 \pm 1,21$} & $0,195^{b}$ \\
\hline NCRT_nt & \multicolumn{2}{|c|}{$3,8 \pm 1,5$} & \multicolumn{2}{|l|}{$4 \pm 1,7$} & \multicolumn{2}{|c|}{$3,95 \pm 1,63$} & $0,667^{a}$ \\
\hline NLR & \multicolumn{2}{|c|}{$3,5 \pm 1,2$} & \multicolumn{2}{|c|}{$3,59 \pm 1,68$} & \multicolumn{2}{|c|}{$3,57 \pm 1,53$} & $0,959^{b}$ \\
\hline \multirow[t]{2}{*}{$\mathrm{HB}(\mathrm{g} / \mathrm{L})$} & \multicolumn{2}{|c|}{$12,1 \pm 2,1$} & \multicolumn{2}{|c|}{$12 \pm 1,8$} & \multicolumn{2}{|c|}{$12,03 \pm 1,9$} & $0,944^{a}$ \\
\hline & n (14) & $\%$ & n (29) & $\%$ & n (43) & $\%$ & \\
\hline \multicolumn{8}{|l|}{ Sex } \\
\hline Female & 7 & 50 & 12 & 41,37 & 18 & 44,18 & \multirow[t]{2}{*}{$0,594^{c}$} \\
\hline Male & 7 & 50 & 17 & 58,62 & 24 & 55,81 & \\
\hline \multicolumn{8}{|l|}{ Pre NCRT Stage } \\
\hline Stage $2 a$ & 4 & 28,57 & 8 & 27,58 & 12 & 27,9 & $0,549^{c}$ \\
\hline Stage $2 b$ & 1 & 7,14 & 2 & 6,89 & 3 & 6,97 & \\
\hline Stage $3 a$ & 3 & 21,42 & 2 & 6,89 & 5 & 11,62 & \\
\hline Stage 3b & 5 & 35,71 & 12 & 41,37 & 17 & 39,53 & \\
\hline Stage $3 c$ & 1 & 7,14 & 5 & 17,24 & 6 & 13,95 & \\
\hline Surgery & & & & & & & \\
\hline APR & 3 & 21,42 & 9 & 31,03 & 12 & 27,9 & $0,511^{c}$ \\
\hline $\begin{array}{l}\text { a: Student's t test, b:Mar } \\
\text { ratio }(p<0,05), \text { SD: Stan } \\
\text { resection, APR: Abdomir } \\
\text { CEA: Carsinoembryonic } \\
\text { NCRT_nt: Pre neoadjuve } \\
\text { HB: hemoglobin. }\end{array}$ & $\begin{array}{l}\text { hitney U } \\
\text { deviatiol } \\
\text { rineal res } \\
\text { gen, NCR } \\
\text { hemorac }\end{array}$ & $\begin{array}{l}\text { st, c:Chi } \\
\text { NCRT: } \\
\text { ction, PI } \\
\text { If: Pre } \\
\text { otherapy }\end{array}$ & $\begin{array}{l}\text { uare tes } \\
\text { adjuvan } \\
\text { perineur } \\
\text { adjuvan } \\
\text { utrophil }\end{array}$ & $\begin{array}{l}\text { t:Fisher } \\
\text { hemora } \\
\text { invasior } \\
\text { hemora } \\
\text { unt, NL }\end{array}$ & $\begin{array}{l}\text { act test, } \\
\text { therapy, } \\
\text { Vl: lymp } \\
\text { therapy } \\
\text { neutroph }\end{array}$ & $\begin{array}{l}\text { efers to } \\
\text { R: Low } \\
\text { vascule } \\
\text { mphocy } \\
\text { o lympt }\end{array}$ & $\begin{array}{l}\text { e higher } \\
\text { terior } \\
\text { ivasion, } \\
\text { count, } \\
\text { cyte ratio, }\end{array}$ \\
\hline
\end{tabular}




\begin{tabular}{|c|c|c|c|c|c|c|c|}
\hline \multirow[b]{2}{*}{ LAR } & \multicolumn{2}{|c|}{ Major Response } & \multicolumn{2}{|c|}{ Minor Response } & \multicolumn{2}{|c|}{ Total } & \multirow[t]{2}{*}{$P$ value } \\
\hline & 11 & 78,57 & 20 & 68,96 & 31 & 72,09 & \\
\hline \multicolumn{8}{|l|}{ Differantiation } \\
\hline Poorly & 0 & 0 & 0 & 0 & 0 & 0 & \multirow[t]{3}{*}{$0,457^{c}$} \\
\hline Moderate & 8 & 57,14 & 23 & 79,31 & 31 & 72,09 & \\
\hline Well & 6 & 42,85 & 6 & 20,68 & 12 & 27,91 & \\
\hline \multicolumn{8}{|l|}{ PNI } \\
\hline Absent & 13 & $92,85^{*}$ & 17 & 58,62 & 30 & 69,76 & \multirow[t]{2}{*}{$0,033^{d}$} \\
\hline Present & 1 & 7,14 & 12 & $41,37 *$ & 13 & 30,23 & \\
\hline \multicolumn{8}{|l|}{ LVI } \\
\hline Absent & 13 & $92,85^{*}$ & 11 & 37,93 & 24 & 55,81 & \multirow[t]{2}{*}{$0,001^{d}$} \\
\hline Present & 1 & 7,14 & 18 & $62,06 *$ & 19 & 44,18 & \\
\hline \multicolumn{8}{|l|}{ Necrosis } \\
\hline Absent & 13 & $92,85^{*}$ & 10 & 34,48 & 23 & 53,48 & \multirow[t]{2}{*}{$<0,001^{d}$} \\
\hline Present & 1 & 7,14 & 19 & $65,51 *$ & 20 & 46,51 & \\
\hline \multicolumn{8}{|c|}{$\begin{array}{l}\text { a: Student's t test, b:Mann Whitney U test, c:Chi-Square test, d:Fisher Exact test, * refers to the higher } \\
\text { ratio ( } p<0,05) \text {, SD: Standart deviation, NCRT: Neoadjuvant chemoradiotherapy, LAR: Low anterior } \\
\text { resection, APR: Abdominoperineal resection, PNI: perineural invasion, LVI: Iymphovasculer invasion, } \\
\text { CEA: Carsinoembryonic antigen, NCRT_ If: Pre neoadjuvant chemoradiotherapy lymphocyte count, } \\
\text { NCRT_ nt: Pre neoadjuvant chemoradiotherapy neutrophil count, NLR: neutrophil to lymphocyte ratio, } \\
\text { HB: hemoglobin. }\end{array}$} \\
\hline
\end{tabular}

A statistically significant relationship was determined between major response to NCRT and the absence of PNI, LVI, and necrosis $(p<0.05)$. In the minor response group, the anal verge distance was observed to be higher $(p=0.013)$. In patients where the tumor was closer than $6 \mathrm{~cm}$ to the anal verge, the response was better. ROC curve showing the relationship between anal verge distance and pathological response are shown in Table 2. The response to treatment was better in patients with no CRM involvement and no EMVI in the MRI evaluations before NRCT, but the difference was not statistically significant. The relationship between the MRI findings and the response to the neoadjuvant therapy were shown in Table 3. The follow-up periods, DFS, OS, metastasis, and mortality rates are shown in Table 4. From the parameters that were significant in univariate analysis, no statistically significant variable was determined in the multivariate analysis.

Table 2: ROC curve showing the relationship between anal verge distance and pathological response. The cut-off point for anal verge distance was found as $\leq 6(p=0,003)$. According to the value $85,71 \%$ of the 
major responses and $60,71 \%$ of the minor responses can be correctly distinguished. Also, the overall performance of the value is calculated as $73,50 \%$.

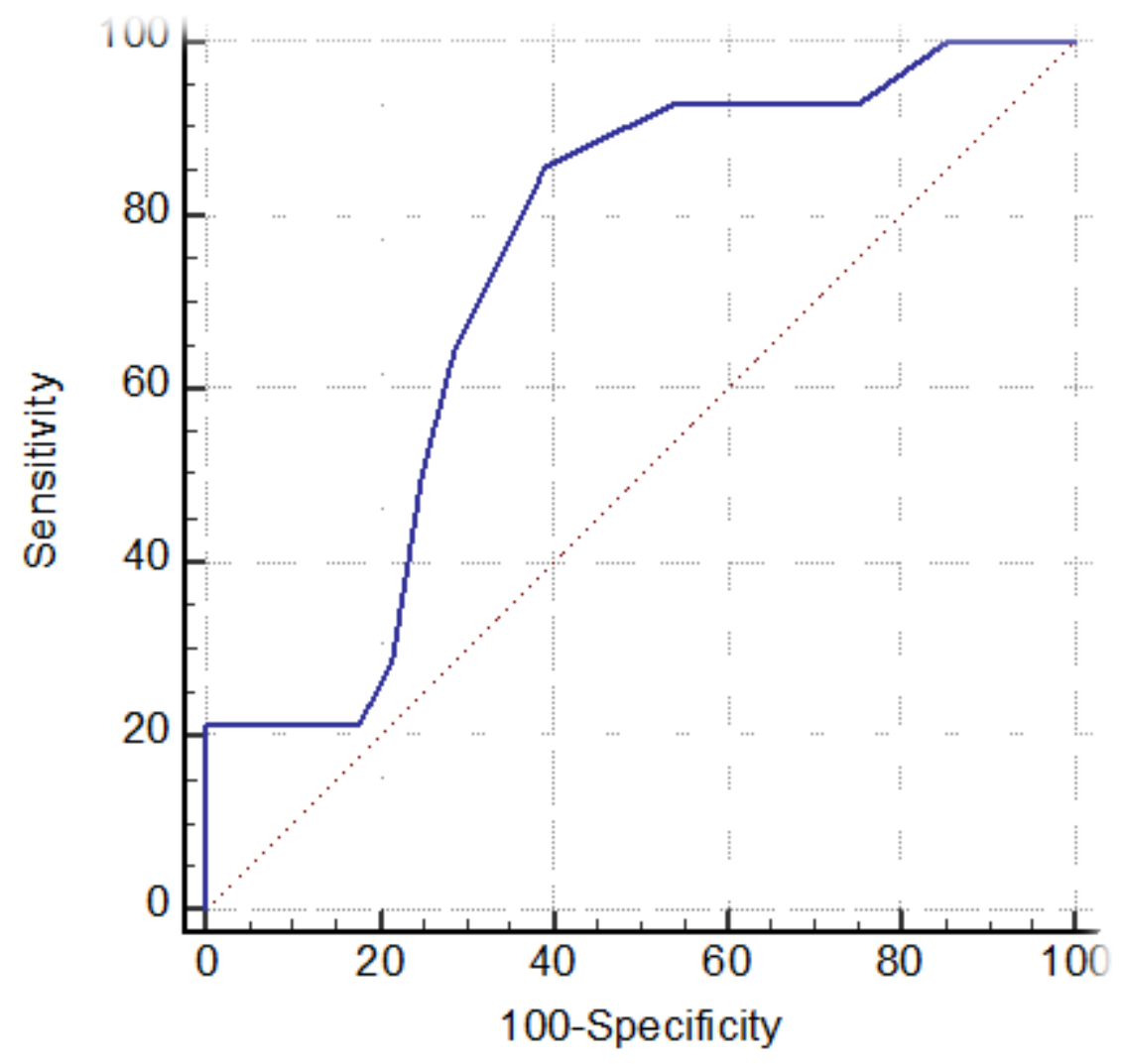


Table 3

Summary of the MRI findings of the patients according to response to the neoadjuvant therapy

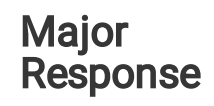

n $\%$

(12)
Minor

Response
Total

$\%$

(27)
$\mathbf{P}$ value

Pre-NCRT MRI T Stage

\begin{tabular}{llllllll} 
T1-2 & 6 & 50,0 & 5 & 18,51 & 11 & 28,20 & $0,127^{C}$ \\
\cline { 1 - 6 } T3 & 4 & 33,33 & 16 & 59,25 & 20 & 51,28 & \\
T4 & 2 & 16,66 & 6 & 22,22 & 8 & 20,51 &
\end{tabular}

Pre-NCRT MRI N Stage

$\begin{array}{llllllll}\text { N0 } & 5 & 41,66 & 6 & 22,22 & 11 & 28,20 & 0,407^{c} \\ \text { N1 } & 6 & 50,0 & 16 & 59,25 & 22 & 56,41 & \\ \text { N2 } & 1 & 8,33 & 5 & 18,51 & 6 & 15,38 & \end{array}$

Pre-NCRT MRI CRM

\begin{tabular}{llllllll|} 
Absent & 9 & 75,0 & 17 & 62,96 & 26 & 66,66 & $0,714^{d}$ \\
\cline { 1 - 6 } Present & 3 & 25,0 & 10 & 37,03 & 13 & 33,33 &
\end{tabular}

Pre-NCRT MRI EMVI

\begin{tabular}{|c|c|c|c|c|c|c|}
\hline Absent & 11 & 91,66 & 17 & 62,96 & 28 & 71,79 \\
\hline Present & 1 & 8,33 & 10 & 37,03 & 11 & 28,20 \\
\hline
\end{tabular}

Pre-NCRT MRI mesorectum invasion

\begin{tabular}{llllllll} 
Absent & 6 & 50,0 & 5 & 18,51 & 11 & 28,20 & $0,061^{\mathrm{d}}$ \\
\cline { 1 - 6 } Present & 6 & 50,0 & 22 & 81,49 & 28 & 71,80 &
\end{tabular}

c:Chi-Square test, d:Fisher Exact test

SD: Standart deviation, NCRT: neoadjuvant chemoradiotherapy, MRI: Magnetic resonans imaging CRM: Circumferential resection margin, EMVI: Extramural venous invasion 
Table 4

Follow up times of the patients, disease free survival (DFS), mean survival (OS) and findings of metastasis and death.

\begin{tabular}{|c|c|c|c|c|c|c|c|}
\hline & \multicolumn{2}{|c|}{ Major Response } & \multicolumn{2}{|c|}{ Minor Response } & \multicolumn{2}{|l|}{ Total } & \multirow[t]{2}{*}{$P$ value } \\
\hline & $\mathrm{n}(14)$ & $\%$ & $\mathrm{n}(29)$ & $\%$ & $\mathrm{n}(43)$ & $\%$ & \\
\hline \multicolumn{7}{|l|}{ Death of disease } & \multirow[t]{3}{*}{$0,071^{d}$} \\
\hline Absent & 13 & 92,85 & 19 & 65,51 & 32 & 74,41 & \\
\hline Present & 1 & 7,14 & 10 & 34,48 & 11 & 25,58 & \\
\hline \multicolumn{7}{|l|}{ Metastasis } & \multirow[t]{3}{*}{$0,564^{c}$} \\
\hline Absent & 12 & 85,71 & 21 & 72,41 & 33 & 76,74 & \\
\hline Present & 2 & 14,28 & 8 & 27,58 & 10 & 23,25 & \\
\hline \multicolumn{8}{|l|}{ Recurrence } \\
\hline Absent & 14 & 100 & 29 & 100 & 43 & 100 & \\
\hline \multirow[t]{2}{*}{ Present } & 0 & 0 & 0 & 0 & 0 & 0 & \\
\hline & \multicolumn{2}{|c|}{ Mean \pm SD } & \multicolumn{2}{|c|}{ Mean \pm SD } & \multicolumn{2}{|c|}{ Mean \pm SD } & \\
\hline Follow-up (month) & \multicolumn{2}{|c|}{$32,7 \pm 17,8$} & \multicolumn{2}{|c|}{$33,8 \pm 20,9$} & \multicolumn{2}{|c|}{$33,44 \pm 19,73$} & $0,969^{b}$ \\
\hline DFS (month) & \multicolumn{2}{|c|}{$30 \pm 13,8$} & \multicolumn{2}{|c|}{$31,7 \pm 21,8$} & \multicolumn{2}{|c|}{$31,14 \pm 19,36$} & $0,688^{b}$ \\
\hline \multicolumn{8}{|c|}{ a: Student's t test, b:Mann Whitney U test, c:Chi-Square test, d:Fisher Exact test } \\
\hline DFS: Disease frees & jival & & & & & & \\
\hline
\end{tabular}

\section{Discussion}

In patients with locally advanced rectal cancer, the standard treatment is NCRT to obtain a full pathological response to treatment. However, PCR is not seen in $80 \%$ of patients, $20 \%$ do not respond to treatment, and $50-60 \%$ of patients achieve a partial response [4]. The ability to identify these patients beforehand would be able to reduce loss of time, eliminate surgical technical difficulties associated with NCRT, and reduce complications such as damage to surrounding tissues and organs.

The studies available in literature to date that have researched the factors affecting PCR following NCRT in rectal cancer were examined, and although there are some studies, such as by Garcia et al., which have not defined any variable related to full response, many studies have defined factors affecting PCR. These factors include the nodal stage of the tumor before treatment, CEA level $<5 \mathrm{ng} / \mathrm{dl}$, and $\mathrm{Hb}$ level $>12.5 \mathrm{~g} / \mathrm{dl}$. 
It is thought that in cases with low hemoglobin, there is angiogenesis and hypoxia in the tumor reducing the response to radiotherapy [17-19].

In a study similar to the current research, Das et al. showed that the circumferential extent of the tumor, CEA level, and anal verge distance had an effect on PCR in patients receiving NCRT. In that study, pretreatment CEA level of $>2.5 \mathrm{ng} / \mathrm{ml}$, circumferential extent of the tumor $>60 \%$, and the tumor $>5 \mathrm{~cm}$ from the anal verge were evaluated as factors reducing the pathological complete response [20]. In a study by Sun et al, a significant relationship was determined between CEA levels and lymph node response in patients receiving NCRT [21].

In the current study, there was no significant relationship between the pathological response and CEA and $\mathrm{Hb}$ levels. However, in patients where the tumor was closer than $6 \mathrm{~cm}$ to the anal verge, the response to NCRT was found to be statistically significantly better.

Other than the $\mathrm{Hb}$ and CEA levels in the preoperative blood tests, the NLR is used to evaluate long-term results in lung, colon, and stomach cancers, and it is thought that anticancer activity is increased associated with an increase in the lymphocyte rate [22]. In a previous study of breast cancer, an increase in PCR was determined when NLR was < 2.06 [23]. Taking these studies into consideration, the NLR was evaluated and the effect on PCR was examined in the current study in addition to $\mathrm{Hb}$ levels, but no significant correlation was determined.

As in the current study, several previous studies have evaluated age and gender, and have not determined an effect on PCR of either $[6,20,21]$.

Huh et al. examined stage 2-3 colorectal cancer patients applied with curative surgery and reported that the presence of LVI and PNI were significant predictors for DFS and OS [24]. Similarly, in a meta-analysis of 38 series by Yang et al., the effects of PNI on DFS and OS were examined, and the expectations of those with invasion were shown to be worse. However, the relationship between PNI and PCR was not examined [25]. Nikberg et al. reported that both LVI and PNI were associated with a poor prognosis, and the presence of these was also related to increased recurrence [26].

In the current study, the tumor response was examined in patients with LVI, PNI and necrosis histopathologically, and the effects of grade and differentiation on response were evaluated. The results of the study demonstrated that PNI, LVI and necrosis affected the pathological response.

In addition to histopathological evaluations, the predictive value of MRI following NCRT in rectal cancer has been investigated in some studies. MRI is a non-invasive diagnostic method that does not expose the patient to radiation. In patients with rectal cancer, CRM, EMVI, tumor size, mesorectum invasion, and lymph node involvement can be evaluated with MRI. The presence of EMVI on MRI before NCRT is an independent poor prognostic factor and has been associated with reduced survival. An increase in the risk of distant metastasis has been determined in EMVI positivity [27-29]. In a study by Prampolini et al., CRM involvement and mr-EMVI before NCRT have been found to be parameters predicting recurrence [15]. 
When the MRI findings were evaluated in the current study, although not statistically significant, there were seen to be fewer patients with mr-EMVI and CRM involvement in the major response to NCRT group, and there were more patients with mesorectum invasion in the minor response group.

In conclusion, of the parameters predicting response to NCRT in rectal cancer, PNI, LVI, necrosis, and anal verge distance were found to be predictive factors. Although not statistically significant, the absence of $\mathrm{mr}-\mathrm{EMVI}$ and CRM involvement were seen to be related to a good response. Age and gender had no effect on response, and of the hematological parameters, $\mathrm{Hb}$ level, CEA and NLR were not found to be significant.

There were some limitations to this study, primarily that the end-point of the study was limited to PCR. The follow-up periods of the patients, OS and DFS were added to the study but the long-term clinical results were not included in the evaluation. Furthermore, the number of patients was limited as it was a single-centre study and there is therefore a need for more extensive studies to be able to reach significant results. To be able to produce similar results and determine the parameters which can predict response to NCRT, the support of further studies is required.

\section{Declarations}

\section{Compliance with Ethical Standarts:}

Conflict of interest: The authors declare that they have no conflict of interest.

Informed consent: Informed consent was not required due to the retrospective use of de-identifed administrative data.

Ethical approval: All procedures performed in studies involving human participants were in accordance with the ethical standards of the institutional and/or national research committee and with the 1964 Helsinki declaration and its later amendments or comparable ethical standards. Approval for this study was granted from XXXX Hospital Ethics Committee for Clinical Studies in July 2020 (reg:83).

Funding: This research did not receive any specific grant from funding agencies in the public, commercial, or not-for-profit sectors.

\section{Authors Contributions}

EY, AME, IY, ZP performed the literature search, database set up and contributed to the writing of the manuscript. EY, SB reviewed the manuscript. POG, FC contributed to the study design and reviewed the manuscript. EY, SB, ZP contributed to the study design, the writing of the manuscript and reviewed the manuscript. All authors are in agreement will all aspects of the final manuscript.

\section{Data availability statement}


The data that support the findings of this study are available on request from the corresponding author. The data are not publicly available due to privacy or ethical restrictions.

\section{References}

1. Bray F, Ferlay J, Soerjomataram I, et al (2018) Global cancer statistics 2018: GLOBOCAN estimates of incidence and mortality worldwide for 36 cancers in 185 countries. CA Cancer J Clin 68:394-424. PMID: 30207593 DOI: 10.3322/caac. 21492.

2. Yang $Y$, Huang $X$, Sun J, et al (2015) Prognostic value of perineural invasion in colorectal cancer: $A$ meta- analysis. J. Gastrointest. Surg. Off. J. Soc. Surg. Aliment. Tract 19:1113-1122. PMID: 25663635 DOI: 10.1007/s11605-015-2761-z.

3. Benson AB, Venook AP, Al-Hawary MM, et al (2018) Rectal Cancer, Version 2.2018, NCCN Clinical Practice Guidelines in Oncology. Journal of the National Comprehensive Cancer Network, 16(7), 874901 PMID: 30006429. DOI:10.6004/jnccn.2018.00

4. Ryan JE, Warrier SK, Lynch AC, et al (2015) Assessing pathological complete response to neoadjuvant chemoradiotherapy in locally advanced rectal cancer: A systematic review. Colorectal Dis. Off. J. Assoc. Coloproctol. Great Br. Irel 17: 849-861. PMID:26260213 DOI: 10.1111/codi.13081.

5. Martin ST, Heneghan HM, Winter DC (2012) Systematic review and meta-analysis of outcomes following pathological complete response to neoadjuvant chemoradiotherapy for rectal cancer. Br J Surg 99: 918-28. PMID: 22362002 DOI: 10.1002/bjs.8702

6. de Campos-Lobato LF, Stocchi L, da Luz Moreira A, et al (2011) Pathologic complete response after neoadjuvant treatment for rectal cancer decreases distant recurrence and could eradicate local recurrence. Ann Surg Oncol 18:1590-8, PMID:21207164 DOI: 10.1245/s10434-010-1506-1

7. Sauer R, Liersch T, Merkel S, et al (2012) Preoperative versus postoperative chemora-diotherapy for locally advanced rectal cancer: results of the German CAO/ARO/AIO-94 randomized phase III trial after a median follow-up of 11 years. J Clin Oncol 30: 1926-33.

PMID:22529255 DOI: 10.1200/jco.2011.40.1836

8. Bosset JF, Collette L, Calais G, et al (2006) Chemotherapy with preoperative radiotherapy in rectal cancer. N. Engl. J. Med 355:1114-1123. PMID: 16971718 DOI: 10.1056/NEJMoa060829

9. Silberfein EJ, Kattepogu KM, Hu CY, et al (2010) Long-term survival and recurrence outcomes following surgery for distal rectal cancer. Ann Surg Oncol 17:2863-9 PMID: 20552409 DOI: 10.1245/s10434-010$1119-8$

10. Couwenberg AM, Burbach JPM, van Grevenstein WMU, et al (2018) Effect of Neoadjuvant Therapy and Rectal Surgery on Health-related Quality of Life in Patients With Rectal Cancer During the First 2 
Years After Diagnosis. Clin Colorectal Cancer 17:e499-

e512 PMID: 29678514 DOI: 10.1016/j.clcc.2018.03.009

11. Ashburn JH, Kalady MF (2016) Radiation-Induced Problems in Colorectal Surgery. Clin Colon Rectal Surg 29:85-91. PMID: 27247532 DOI: 10.1055/s-0036-1580632

12. Delphine Dayde, Ichidai Tanaka, Jain R, et al (2017) Predictive and Prognostic Molecular Biomarkers for Response to Neoadjuvant Chemoradiation in Rectal Cancer J Mol Sci Mar 7;18(3):573 PMID: 28272347 DOI: $10.3390 / \mathrm{ijms} 18030573$

13. Weiser MR (2018) AJCC 8th Edition: Colorectal Cancer. Ann Surg Oncol 25(6):1454-1455. PMID: 29616422 DOI: 10.1245/s10434-018-6462-1

14. Nougaret S, Reinhold C, Mikhael HW, et al (2013) The use of MR imaging in treatment planning for patients with rectal carcinoma: have you checked the "DISTANCE"? Radiology 268: 330-44.

PMID: 23882096 DOI: 10.1148/radiol.13121361

15. Prampolini F, Taschini S, Pecchi A, et al (2020) Magnetic resonance imaging performed before and after preoperative chemoradiotherapy in rectal cancer: predictive factors of recurrence and prognostic significance of MR-detected extramural venous invasion. Abdom Radiol (NY) 45(10):2941-

2949. PMID: 30483843 DOI: 10.1007/s00261-018-1838-z

16. Mage AG, Pai RK, Stocchi L, et al (2015) American Joint Committee on Cancer and College of American Pathologists regression grade: a new prognostic factor in rectal cancer. Dis Colon Rectum 58(1):32-44.PMID: 25489692 DOI: 10.1097/DCR.0000000000000266

17. García-aguilar J, Hernandez de Anda E, Sirivongs P, et al (2003) A pathologic complete response to preoperative chemoradiation is associated with lower local recurrence and improved survival in rectal cancer patients treat- ed by mesorectal excision. Dis Colon Rectum 46:298-304. PMID: 12626903 DOI: $10.1007 /$ s10350-004-6545-x

18. Yoon SM, Kim DY, Kim TH, et al (2007) Clinical parameters predicting pathologic tumor response after preoperative chemoradiotherapy for rectal cancer. Int J Radiat Oncol Biol Phys 69:1167-

72. PMID: 17967307 DOI: 10.1016/j.jijrobp.2007.04.047

19. Varlotto J, Stevenson MA (2005) Anemia, tumor hypoxemia, and the cancer patient. Int J Radiat Oncol Biol Phys 63:25-36. PMID: 16111569 DOI: 10.1016/j.ijrobp.2005.04.049

20. Das P, Skibber JM, Rodriguez-Bigas MA, et al (2007) Predictors of tumor response and downstaging in patients who receive preop- erative chemoradiation for rectal cancer. Cancer 109: 1750-1755. PMID: 17387743 DOI: $10.1002 /$ cncr.22625.

21. Sun $Y$, Wu X, Lin H, et al (2021) Lymph Node Regression to Neoadjuvant Chemoradiotherapy in Patients with Locally Advanced Rectal Cancer: Prognostic Implication and a Predictive Model Journal of 
Gastrointestinal Surgery. 25(4):1019-1028. PMID: 32219686 DOI: 10.1007/s11605-020-04566-x

22. Shivakumar L, Ansell S (2006) Targeting B-lymphocyte stimulator/B-cell activating factor and a proliferationinducing ligand in hematologic malignancies. Clin Lymphoma Myeloma 7: 106-108 PMID: 17026820 DOI: 10.3816/CLM.2006.n.046.

23. ChenY, Chen K, Xiao X, et al (2016) Pretreatment Neutrophil-To-Lymphocyte Ratio Is Correlated With Response to Neoadjuvant Chemotherapy as an Independent Prognostic Indicator in Breast Cancer Patients: A Retrospective Study. BMC Cancer 19; 16:320. PMID:27198767 DOI: 10.1186/s12885-0162352-8

24. Huh JW, Lee JH, Kim HR, et al (2013) Prognostic significance of lymphovascular or perineural invasion in patients with locally advanced colorectal cancer. The American Journal of Surgery 206(5), 758-763. PMID:23835209 DOI: 10.1016/j.amjsurg.2013.02.010

25. Yuchong Yang, Xuanzhang Huang, Jingxu Sun, et al (2015) Prognostic Value of Perineural Invasion in Colorectal Cancer: A Meta-Analysis J Gastrointest Surg 19(6):1113- 22 PMID:25663635 DOI 10.1007/s11605-015-2761-z

26. Nikberg $\mathrm{M}$, Chabok $\mathrm{A}$, Letocha $\mathrm{H}$, et al (2016) Lymphovascular and perineural invasion in stage II rectal cancer: a report from the Swedish colorectal cancer registry. Acta Oncologica 55(12), 1418-1424. PMID: 27732105 DOI:10.1080/0284186x.2016.1230274

27. Tripathi, P, Rao SX, Zeng, MS (2017) Clinical value of MRI-detected extramural venous invasion in rectal cancer. Journal of Digestive Diseases 18(1), 2-12. PMID: 28009094 DOI: 10.1111/17512980.12439

28. Smith NJ, Barbachano Y, Norman AR, et al (2018) Prognostic significance of magnetic resonance imaging-detected extramural vascular invasion in rectal cancer. Br J Surg 95:229-36 PMID: 17932879 DOI: $10.1002 /$ bjs.5917

29. Sohn B, Lim JS, Kim H, et al (2015) MRI-detected extramural vascular invasion is an independent prognostic factor for synchronous metastasis in patients with rectal cancer. Eur Radiol 25:1347-55. PMID: 25500963 DOI: 10.1007/s00330-014-3527-9

\section{Figures}




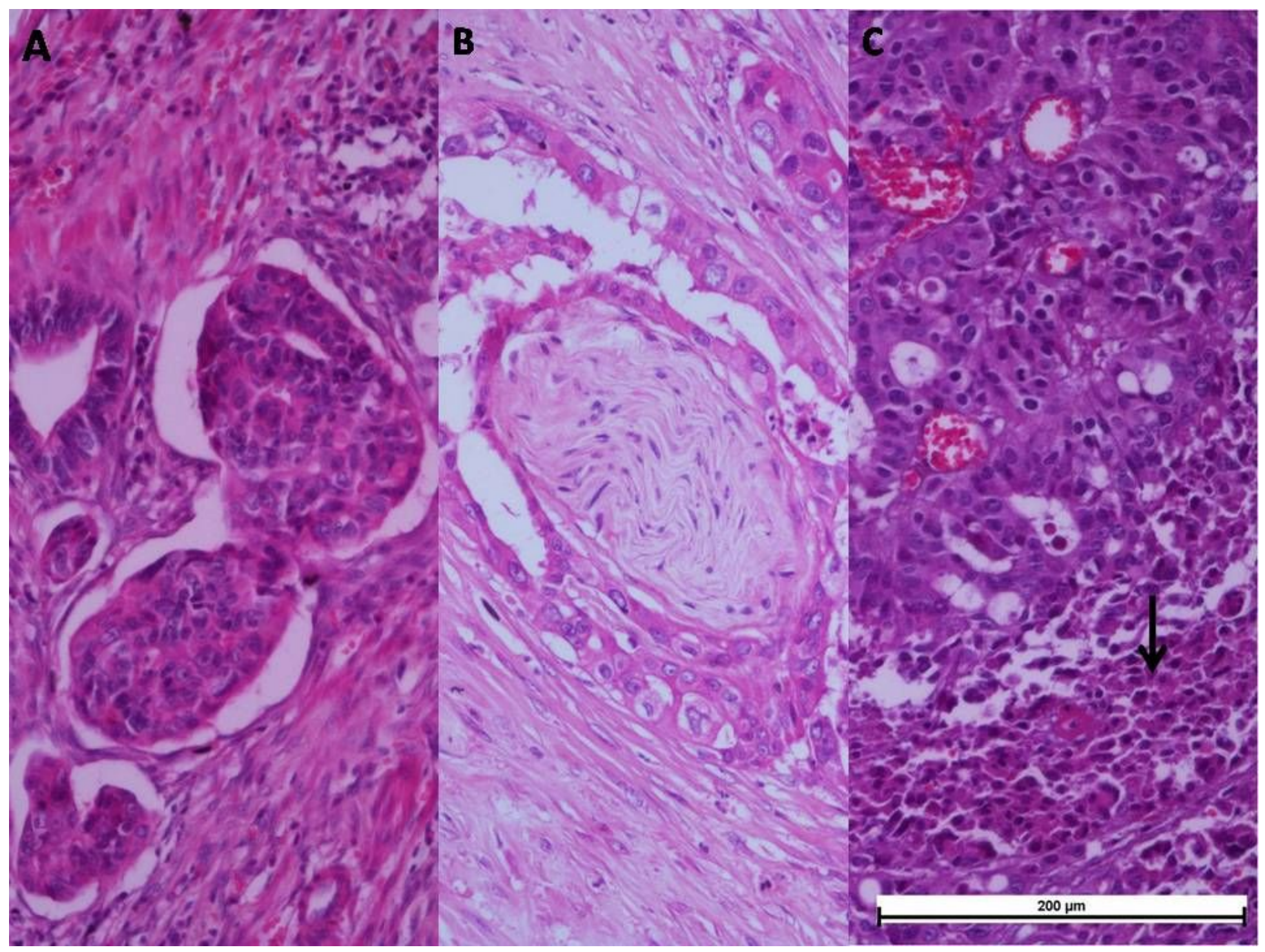

\section{Figure 1}

Perineural invasion and lymphovascular invasion of rectal cancer specimen. A. Lymphovascular invasion (H\&E stain $\times 200)$ B. Perineural invasion (H\&E stain x200) C. Necrosis 